\section{EFFECTS OF ALPHA AND GAMMA RADIATION ON GLASS REACTION IN AN UNSATURATED ENVIRONMENT}

DE91 010272

DAVID J. WRONKIEWICZ, JOHN E. YOUNG, AND JOHN K. BATES Chemical Technology Division, Argonne National Laboratory, 9700 South Cass Avenue, Argonne, IL 60439-4837

\title{
ABSTRACT
}

Radiation may effect the long-term performance of glass in an unsaturated repository site by interacting with air, water vapor, or liquid water. The present study examines (1) the effects of alpha or gamma irradiation in a water vapor environment, and (2) the influence of radiolytic products on glass reaction. Results indicate that nitric and organic acids form in an irradiated water vapor environment and are dissolved in thin films of condensed water. Glass samples exposed to these conditions react faster and have a different assemblage of secondary phases than glasses exposed to nonirradiated water vapor environments.

\section{INTRODUCTION}

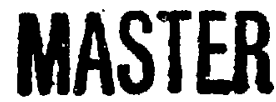

Many studies have been performed to investigate the effects of radiation on glass leaching. These studies have focused on (1) radiationinduced changes to the glass structure and (2) radiation-induced influences on solution chemistry and leaching performance of glass. In general, under saturated test conditions (complete immersion of glass in hydrothermal solution), the following conclusions have been reached:

(1) Radiation damage of the glass is not manifested in major changes in glass leaching performance [1-3].

(2) Gamma irradiation of aerated liquid water results in formation of $\mathrm{OH}_{1} \mathrm{H}_{2} \mathrm{O}_{2}$, and $\mathrm{O}_{2}^{-}$[2], but at dose rates expected for waste storage $\left(\sim 8 \times 10^{3} \mathrm{rad} / \mathrm{h}\right)$ there is a minimal effect on glass leaching [4].

(3) Gamma irradiation of water vapor and air forms nitrogenous species which dissolve in water to form nitrogen acids. Tests conducted with deionized water and large dose rates $\left(\sim 1 \times 10^{6} \mathrm{rad} / \mathrm{h}\right)$ show a pH drop and increase in glass reactivity [5-6]. In leach tests with tuff groundwater, the leachate $\mathrm{pH}$ is buffered by bicarbonate and the glass reaction rate is not affected [7-11].

(4) Gamma irradiation of a $\mathrm{CO}_{2}-\mathrm{H}_{2} \mathrm{O}$ system can result in the formation of organic acids (oxalate and formate). Such acids are of concern because of their ability to complex radionuclides and increase actinide solubility $[5,12,13]$.

The general conclusion from these studies is that under conditions of complete immersion of glass in water, i.e., small surface area of glass/volume of liquid $(S A / V)$ ratios and gas/liquid volume (G/L) ratios, radiation has minimal effect on glass performance.

In this paper, we describe an experimental program designed to evaluate radiation effects under unsaturated conditions representative of the environment expected at Yucca Mountain, Nevada. Under these high SA/V and $G / L$ ratio conditions, radiolytic products will be concentrated in either thin films of water condensed on the waste package or in small volumes of standing water that may accumitate during episodes of water ingress [14]. This paper also presents results that evaluate the effects of both gamma and alpha irradiation on high $\mathrm{G} / \mathrm{L}$ environments, and then examines the influence of radiation on the alteration of glass and formation of secondary mineral phases. 


\section{DISCLAIMER}

This report was prepared as an account of work sponsored by an agency of the United States Governmerit. Neither the United States Government nor any agency thereof, nor any of their employees, makes any warranty, express or implies, or assumes any legal liability or responsibility for the accuracy, completeness, or usefulness of any information, apparatus, product, or process disclosed, or represents that its use would not infringe privately owned rights. Reference herein to any specific commercial product, process, or service by trade name, trademark, manufacturer, or otherwise does not necessarily constitute or imply its encorsement, recoinmendation, or favoring by the United States Government or any agency thereof. The views and opinions of authors expressed herein do not necessarily state or reflect those of the United States Government or any agency thereof. 
At the time of glass production, the dose rate of gamma radiation from a container of glass will be approximately $8 \times 10^{3} \mathrm{rad} / \mathrm{h}$ [15]. The gamma field will decrease by more than three orders of magnitude during the first 1000 years of storage. Thus, the effects of gamma radiation on glass performance will be important only under unanticipated conditions of premature canister breach and water ingress. The glass will also contain long-lived alpha-producing actinides such as Pu-239 and Pu-240. The initial concentrations of these two radionuclides are $3.48 \times 10^{-3}$ and $2.34 \times 10^{-3} \mathrm{Ci} / 1 \mathrm{~b}$ glass, and the half lives are 2400 and 6580 years, respectively [15]. Due to their longer half lives, the radiation field produced by aipha-emitters is expected to dominate during the later stages of the service life of the repository.

Only alpha particles produced within approximately $10^{-4} \mathrm{~cm}$ of the glass surface may escape from the waste and contribute to radiolysis reactions. Using the actinide concentration data of Aines for a 1000-year-old glass waste form [16], an alpha dose rate of $20 \mathrm{rad} / \mathrm{h}$ is expected to be emitted and absorbed within a $4 \mathrm{~cm}$ air layer above the glass.

As indicated earlier, the greatest potential for radiation to affect glass reaction is through the formation of radiolytic products in the gas phase followed by dissolution of these species in a thin film of liquid water contacting the glass. Experimental evidence obtained during gamma irradiation of a two-phase air/water system indicates a reaction efficiency (G value) of $\sim 2$ molecules of $\mathrm{NO}_{3}$ - produced for each $100 \mathrm{eV}$ of energy absorbed $[17]$. Using this $G$ value, the $G / L$ ratio, the dose rate, and the concentration of $\mathrm{N}_{2}$ in the gas phase, the amount of nitric acid produced in the system can be calculated by using an equation presented by Burns et al. [4].

Under long term storage conditions, after most of the gamma-producing nucliodes have decayed, alpha radiolysis may result in continued production of nitric acid. Any alpha particles escaping the glass would also escape into the air if the thin $\mathrm{fjlm}$ of water adsorbed on the glass is less than $4 \times 10^{-3} \mathrm{~cm}$ in thickness. The $\mathrm{HNO}_{3}$ production by alpha particles in moist air is expected to be the same as for gamma radiation [18], al though there is a lack of high $G / L$ ratio experimental data to support this theory.

\section{EXPERIMENTAL CONFIGURATION, RESULTS, AND DISCUSSION}

Experiments were performed to demonstrate that under anticipated longterm unsaturated conditions, where dose rates are less than those examined by Burns but the $G / L$ ratios are far greater, whether measurable concentrations of radiolytic products can be detected in solution. These initial tests were conducted with no glass present. If radiolytic products are not concentrated in the small volumes of liquid present, then it is unlikely that radiation will affect glass performance and further tests involving glass will be unnecessary.

\section{Alpha Blank Tests}

Blank tests (no glass present) were performed to study the alpha radiolysis of a moist air system at room temperature. Each test was performed in duplicate using two sample assembly rod configurations. For both configurations the source of alpha particles was a $1500 \mu \mathrm{Ci} 24 i_{\mathrm{Am}}$ foil with 4.6 MeV energy/alpha decay. In initial tests, the foil was cemented to a lucite rod (Figure 1), while in later experiments it was attached to a type 304 stainless steel rod to eliminate potential sources of organic carbon. The support rod was attached to the underside of a thin meta? 


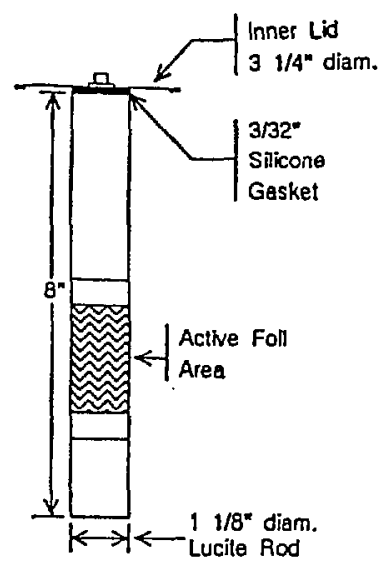

Figure 1. Alpha Radiation

Experimental

Apparatus

support plate and the entire assembly enclosed in a 1.9 liter glass container. The $\mathrm{G} / \mathrm{L}$ ratio of the experimental setup was $100 \mathrm{~L} / \mathrm{L}$ (1800 Cc air/18 mL water) and the gas phase is assumed to be saturated with water vapor $\left[\mathrm{P}_{\mathrm{H} 2 \mathrm{O}}\left(25^{\circ} \mathrm{C}\right)=23\right.$ torr]. The dimensions of the glass container allowed the entire alpha dose escaping from the foil to be absorbed in the air with none of the radiation impinging on the glass container or lid.

Alpha-foil dosimetry tests were performed at room temperature to determine the fraction of energy transferred to the gas phase. Approximately $50 \%$ of the alpha energy is lost due to absorption by a thin protective layer of gold present on the outer surface of the foil. The $\mathrm{N}_{2} \mathrm{O}$ dosimeter was used, where $\mathrm{N}_{2}$ is generated with a $\mathrm{G}$ value of 10.0 molecules $/ 100 \mathrm{eV}$. The dosimeter was operated with $\mathrm{N}_{2}$ analysis performed by gas chromatography after $0,2,7,17$, and 24 days. Nitrogen production was linear as a function of time and indicated that about $37 \%$ of the energy nominally produced by the foil is deposited in the gas phase.

Radiolysis tests were next run for time periods up to 130 days. Upon completion of each run, the foil was removed and samples of water remaining in the vessel bottom (originally DIW) were analyzed for $\mathrm{pH}$, carbon, and anions. The surfaces of the foil, the foil support, and the walls of the glass container were next sprayed with a fine mist of water to flush to the bottom any radiolysis products that had condensed on the solid surfaces. Samples of the rinse water were also analyzed for $\mathrm{pH}$, carbon, and anions.

Significant amounts of nitrate and carbon (both inorganic and organic) were produced during the tests (Table I and Figure 2). Only minor amounts of $\mathrm{Cl}^{-}, \mathrm{F}^{-}, \mathrm{SO}_{4}=$, and $\mathrm{NO}_{2}-$ were detected, either in the surface rinse fraction or bulk solution. Nitrate and nitrite were concentrated in the surface rinse fraction and the total production of these species is consistent with that predicted using a $G$ value of 1.9 molecules $/ 100 \mathrm{eV}$ (Figure 2, dashed line). These results indicate that alpha irradiation of an air atmosphere saturated with water vapor culminates in the concentration of nitrate and nitrite in the thin films of water covering the solid surfaces and, to a lesser extent, in standing water at the bottom of the test vessel.

The carbon results are less consistent than those for nitrate. Both organic and inorganic carbon concentrations increase in alpha irradiated tests using lucite support rods (Table I). Results from the tests using stainless steel support rods do not show any consistent temporal variations, yet increases are noted in inorganic and especially organic carbon concentrations of the rinse fraction. These results suggest that some of the carbon in the tests with a Iucite rod is being derived from the lucite rods themselves. The increase in organic carbon in the stainless steel rod supported tests, however, indicates that some organic carbon is being produced in these experiments from $\mathrm{CO}_{2}$ [5]. 
Results from Alpha Blank Runs

Experiments Conducted at $25^{\circ} \mathrm{C}$ with Lucite Support Rods

Reported Analytical Accuracy Within 10\%

\begin{tabular}{|c|c|c|c|c|c|c|}
\hline $\begin{array}{l}\text { Test No. } \\
\text { Test Length, days } \\
\text { pH }\end{array}$ & $\begin{array}{l}14-\mathrm{A} 1 \\
22\end{array}$ & $\begin{array}{l}14-A 2 \\
22\end{array}$ & $\begin{array}{l}28-A 1 \\
31\end{array}$ & $\begin{array}{l}28-A 2 \\
31\end{array}$ & $\begin{array}{l}56-A 1 \\
65\end{array}$ & $\begin{array}{l}56-A 2 \\
65\end{array}$ \\
\hline $\begin{array}{l}\text { In } \\
\text { Out, before Wash } \\
\text { Out, after Wash }\end{array}$ & $\begin{array}{l}5.50 \\
7.05 \\
7.25\end{array}$ & $\begin{array}{l}5.50 \\
6.90 \\
6.65\end{array}$ & $\begin{array}{l}5.53 \\
4.94 \\
5.54\end{array}$ & $\begin{array}{l}5.53 \\
3.60 \\
4.13\end{array}$ & $\begin{array}{l}5.53 \\
3.83 \\
4.19\end{array}$ & $\begin{array}{l}5.53 \\
4.18 \\
4.60\end{array}$ \\
\hline $\begin{array}{l}\text { Conc. in ppmd } \\
\text { Org. C before Wash } \\
\text { Org. C after Wash } \\
\text { Inorg. C before Wash } \\
\text { Inorg. C after Wash } \\
\mathrm{Cl} \text { - before Wash } \\
\mathrm{Cl}^{-} \text {after Wash } \\
\mathrm{SO}_{4}^{2-} \text { before Wash } \\
\mathrm{SO}_{4}^{2-} \text { after Wash } \\
\mathrm{NO}^{-} \text {before Wash } \\
\mathrm{NO}^{-} \text {- after Wash } \\
\mathrm{NO}_{2}-\text { before Wash } \\
\mathrm{NO}_{2}-\text { after Wash } \\
\mathrm{F}^{-} \text {before Wash } \\
\mathrm{F}^{-} \text {after Wash } \\
\text { Oxalate before Wash } \\
\text { Oxalate after Wash } \\
\text { Formate before Wash } \\
\text { Formate after Wash } \\
\text { Other }\end{array}$ & $\begin{array}{c}7.6 \\
14 \\
4.0 \\
6.8 \\
<0.3 \\
<0.3 \\
\langle 1 \\
<1 \\
2.3 \\
2.5 \\
<0.4 \\
1.1 \\
<0.3 \\
0.3 \\
<1 \\
<1 \\
2.8 \\
3.2 \\
a\end{array}$ & $\begin{array}{c}14 \\
19 \\
4.7 \\
6.4 \\
0.5 \\
2.2 \\
<1 \\
2.3 \\
9.8 \\
8.2 \\
<0.4 \\
0.8 \\
0.5 \\
0.4 \\
<1 \\
<1 \\
<0.6 \\
<0.6 \\
a, b\end{array}$ & $\begin{array}{c}44 \\
c \\
8.6 \\
c \\
<0.5 \\
1.1 \\
1.3 \\
2.7 \\
3.8 \\
13 \\
3.7 \\
1.8 \\
<0.6 \\
<0.6 \\
1.3 \\
1.6 \\
3.3 \\
4.7 \\
a, b\end{array}$ & $\begin{array}{c}44 \\
c \\
7.3 \\
c \\
<0.6 \\
1.2 \\
<0.6 \\
2.8 \\
8.3 \\
16 \\
0.4 \\
<0.2 \\
<0.6 \\
<0.6 \\
0.8 \\
0.9 \\
8.1 \\
3.8 \\
a\end{array}$ & $\begin{array}{l}63 \\
27 \\
11 \\
8.1 \\
<1 \\
<1 \\
<5 \\
<5 \\
13 \\
33 \\
<1 \\
<1 \\
2.3 \\
1.2 \\
<5 \\
<5 \\
<2 \\
<2 \\
a\end{array}$ & $\begin{array}{l}55 \\
28 \\
15 \\
9.1 \\
<1 \\
<1 \\
<5 \\
<5 \\
14 \\
38 \\
<1 \\
<1 \\
4.3 \\
1.8 \\
<5 \\
<5 \\
14 \\
11 \\
a\end{array}$ \\
\hline
\end{tabular}

aAlso unidentified organic acids.

bFoil dropped to bottom.

CAnalysis not carried out.

dReported analytical accuracy within 5 to $10 \%$.

\section{Gamma Blank Tests}

Tests have also been carried out at room temperature in a gamma radiation field. These tests were done at a $G / L$ of 100 and a dose rate of $3.6 \times 10^{3} \mathrm{rad} / \mathrm{h}$. The tests were performed in $22 \mathrm{~mL}$ type $304 \mathrm{~L}$ stainless steel pressure vesse?s with $0.22 \mathrm{~mL}$ of DIW added to each vessel. As with the alpha blank tests, samples of both prerinse and rinse solutions were analyzed.

The data are shown in Figure 3 . The amounts of nitrate and nitrite are greater in solution rinsed from the vessel walls than in the bulk liquid at the bottom of the vessel. This pattern is the same as that found in the alpha blank experiments. The amount of nit ate and nitrite formed is greater than that predicted using $G=1.9$ molecules $/ 100 \mathrm{eV}$ [17] (straight line in Figure 3). A positive $y$-intercept of a line extrapolated from the rinse solution data (not shown in Figure 3) may be indicative of low dosimetry measurements for these samples. Under these experimental conditions, the nitric acid produced by radiolysis and dissolved into the condensed water is predicted to result in a pH of about 3.9 after 7 days. 


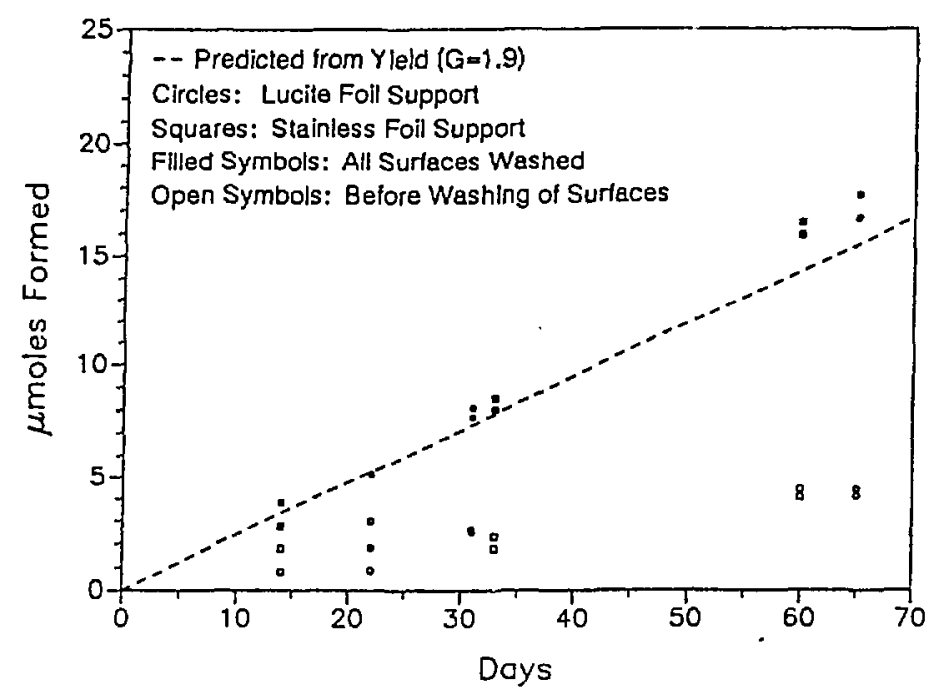

Figure 2. Nitrate + Nitrite Formation in Alpha Blank Tests

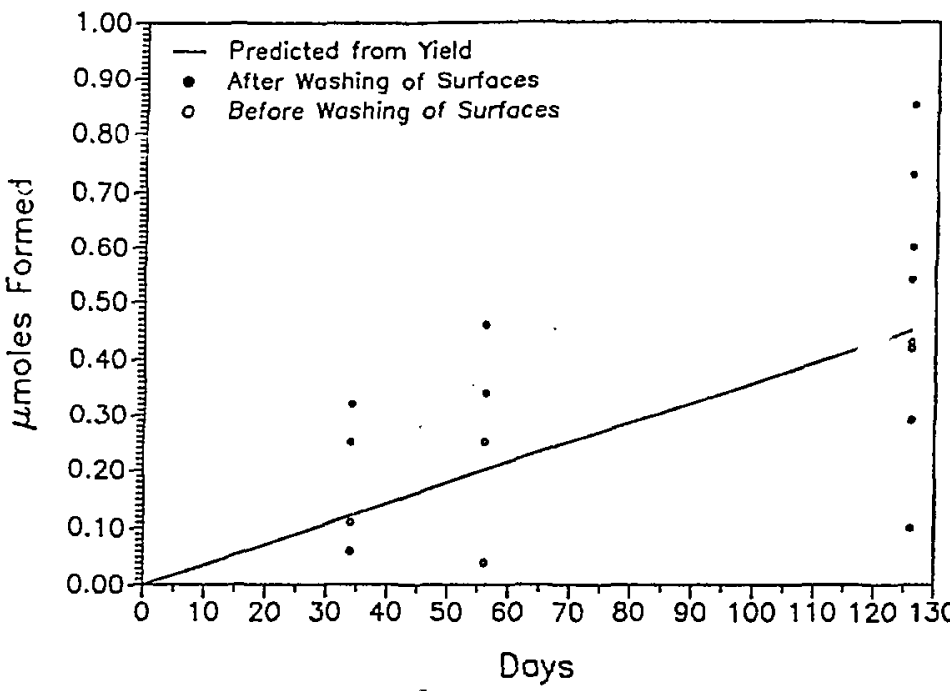

Figure 3. Nitrate + Nitrite Formation in Gamma Blank Tests

\section{Glass Reaction}

The reaction of glass is being examined in both water vapor and liquid water environments but only the vapor tests will be described here. Water vapor contact with the glass may result in hydration aging and alteration, which may ultimately affect the release of radionuclides when the hydrated glass is contacted by groundwater [19]. The reaction occurs in a thin film of water sorbed onto the glass surface. The result of hydration is the formation of a hydrated layer penetrating into the glass and the development of secondary mineral phases on the reacted surface [20]. These phases include clays, zeolites, and calcium silicates, the formation of which is sensitive to the $\mathrm{pH}$ of solution from which they precipitate. These minerals may therefore incorporate some radionuclides into their structures and may control radionuclide release during subsequent glass leaching. Thus, radiation may be an important parameter affecting both the rate of glass hydration and the stability of secondary phases formed.

The goal of the initial vapor hydration studies is to determine if high dose rates will influence the hydration aging of glass. Previous investigations note the formation of secondary phases during exposure of glass to water vapor in a radiation field [21], but comparative studies between irradiated and nonirradiated conditions have not been made. The present study compares the reactivities of a SRL 202 frit based glass doped 
with the transuranic isotopes $237 \mathrm{~Np}, 239 \mathrm{Pu}$, and $241_{\mathrm{Am}}$ and a uraniumcontaining analog (202A and 202U, respectively; Table II). These glasses have compositions similar to those anticipated to be produced in the Defense Waste Processing Facility (DWPF) [15].

A duplicate series of batch hydration tests were performed with each glass. The experimental setup consists of two glass disks suspended in a $304 \mathrm{~L}$ type stainless steel reaction vessel [10]. $0.25 \mathrm{~mL}$ of deionized water was added to each vessel (total vessel volume $22 \mathrm{cc}$ ) to maintain water vapor saturation of the air in the vessel. The present tests were conducted at $200^{\circ} \mathrm{C}$. Previous studies suggest that in the range of $70-240^{\circ} \mathrm{C}$, the hydration mechanism is unchanged [22] and thus elevated temperatures can be used to accelerate testing. The vapor pressure of water under these conditions is about $14 \mathrm{~atm}$, much higher than those possible in the repository. While the radiolytic yields and nature of radiolytic products will differ as a function of the water vapor pressure and temperature [23], the goal of these experiments is to determine if radiation affects the glass reaction. These extreme temperature and pressure conditions are required to attain a measurable extent of reaction during the timeframe of the experiments.

At the end of each test period the vessels were cooled in ice to condense vapor on the vessel bottom. The vessels were next opened, and the $\mathrm{pH}$ of the bottom liquid was measured to determine whether any refluxing had occurred with the liquid condensed on the glass sample. In all cases where the glass remained suspended, the solution $\mathrm{pH}$ was $\sim 6$ indicating no refluxing occurred. In those tests where the glass had disintegrated and fallen onto the vessel bottom (see below), the pH was $\sim 11$. The glasses were next removed and examined to qualitatively determine the extent of reaction. The reaction rate is measured by the thickness of the hydrated glass layer and by the amount and type of secondary mineral phases on the surface.

The $202 \mathrm{~A}$ glass was exposed to an external gamma radiation field of $3.6 \times 10^{3} \mathrm{rad} / \mathrm{h}$ and an alpha field (from the glass) of $\sim 100 \mathrm{rad} / \mathrm{h}$. These glasses reacted to form discrete secondary phases after just 7 days. After 35 days of reaction, the secondary phases include analcime, weeksite, and tobermorite. Between 35 and 65 days the reaction had progressed to a point where the glass had reacted completely through the $2 \mathrm{~mm}$ thickness, and segments of the reacted surface had fallen to the bottom of the vessel. A photomicrograph of $202 \mathrm{~A}$ glass reacted for 35 days is shown in Figure $4 a$. Here it is seen that a multilayer structure penetrates into the glass and the surface layers are buckled and crumbling.

TABLE II

$202 \mathrm{U}$ and 202A Glass Compositions (in oxide weight percent)

\begin{tabular}{|c|c|c|c|c|c|}
\hline & $202 U$ & $202 A$ & & $202 U$ & $202 A$ \\
\hline $\begin{array}{l}\mathrm{SiO}_{2} \\
\mathrm{~B}_{2} \mathrm{O}_{3} \\
\mathrm{Li}_{2} \mathrm{O} \\
\mathrm{Na}_{2} \mathrm{O} \\
\mathrm{MgO} \mathrm{O} \\
\mathrm{CaO} \\
\mathrm{TiO}_{2} \\
\mathrm{~F}_{2} \mathrm{O}_{3} \\
\mathrm{Al}_{2} \mathrm{O}_{3} \\
\mathrm{MnO}_{2} \\
\mathrm{~K}_{2} \mathrm{O}^{2}\end{array}$ & $\begin{array}{r}51.66 \\
8.13 \\
4.80 \\
6.81 \\
1.49 \\
0.80 \\
1.33 \\
12.16 \\
4.73 \\
3.50 \\
3.24\end{array}$ & $\begin{array}{r}48.95 \\
7.97 \\
4.23 \\
8.92 \\
1.32 \\
1.20 \\
0.91 \\
11.41 \\
3.84 \\
2.21 \\
3.71\end{array}$ & $\begin{array}{l}\mathrm{ZrO}_{2} \\
\mathrm{La}_{2} \mathrm{O}_{3} \\
\mathrm{NiO} \\
\mathrm{SrO} \\
\mathrm{Cs}_{2} \mathrm{O} \\
\mathrm{U}_{3} \mathrm{O}_{8} \\
\mathrm{Am}^{2}-241 \\
\mathrm{~Np}-237 \\
\mathrm{Pu}-238 \\
\mathrm{Tc}-99\end{array}$ & $\begin{array}{l}- \\
- \\
1.03 \\
0.16 \\
0.19 \\
1.38 \\
- \\
- \\
- \\
-\end{array}$ & $\begin{array}{l}0.10 \\
- \\
0.82 \\
0.03 \\
- \\
1.93 \\
0.0004 \\
0.01 \\
0.01 \\
0.02\end{array}$ \\
\hline
\end{tabular}



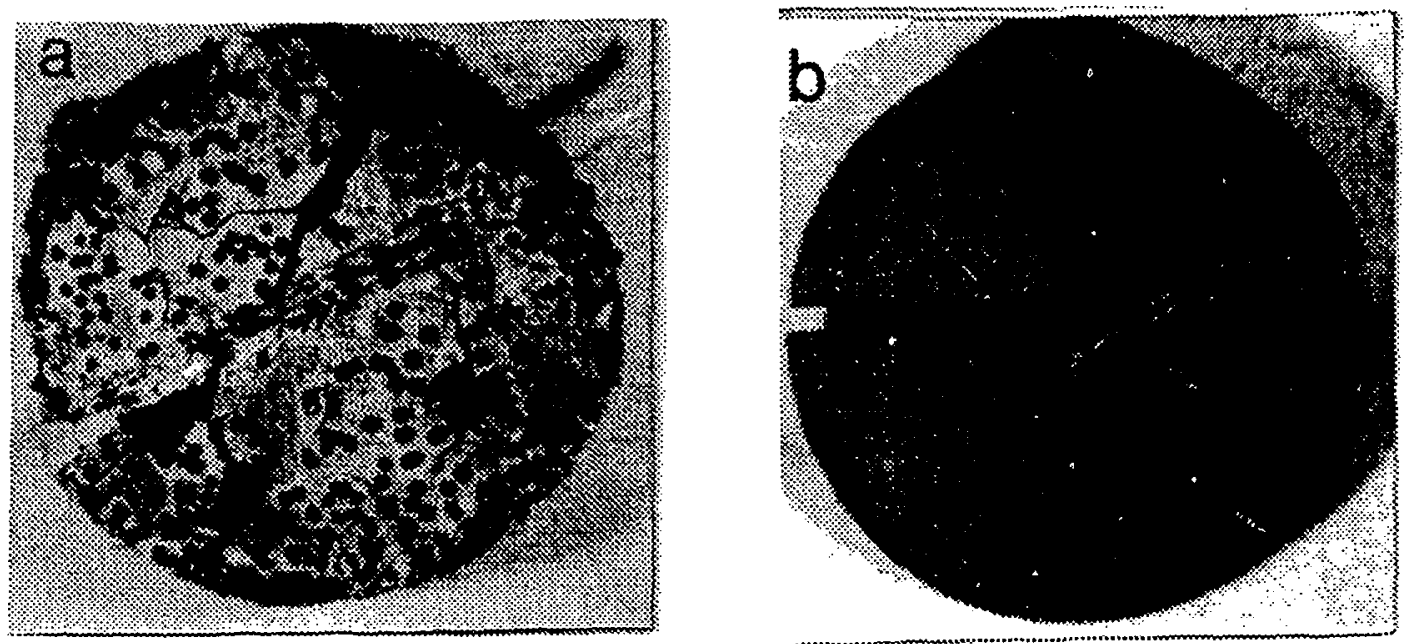

Figure 4. Photomicrograph of (a) the Surface of 202A Glass Hydrated at $200^{\circ} \mathrm{C}$ in a Gamma Radiation Field of $\sim 5000 \mathrm{rad} / \mathrm{h}$, (b) $202 \mathrm{U} \mathrm{Glass}$ Hydrated at $200^{\circ} \mathrm{C}$ Without Radiation. The experimental duration of both samples was 35 days. The diameter of the glass wafers is $\sim 1.3 \mathrm{~cm}$. Note the $202 \mathrm{~A}$ glass has developed a thick alteration cover with relatively large secondary precipitates while the $202 \mathrm{U}$ glass has developed only a thin alteration cover.

The $202 \mathrm{U}$ glass was hydrated under identical conditions, but without radiation exposure. These tests also were run from between 7 to 65 days. The 35-day $202 \mathrm{U}$ glass reaction is shown in Figure 4b. In this sample no unique secondary phases have nucleated but instead a hydroscopic, "salt" rich film has formed on the surface. This film remains damp until dried in a heat lamp at which time isolated evaporite crystals form. Examination of the cross-section of reacted glass reveals a layer several microns thick which remains attached to the glass. After 65 days, one sample had reacted to the point equivalent to the 7-day 202A sample where isolated calcium silicate phases can be identified and a reaction layer 10-15 $\mu \mathrm{m}$ has formed.

Because the hydration process and extent of reaction is dependent on the onset of phase nucleation [19], a second set of $202 \mathrm{U}$ tests were conducted. This series yielded more rapid nucleation of secondary phases. After 35 days, discrete phases including analcime, weeksite, and unidentified $\mathrm{Ca}+\mathrm{Si}, \mathrm{Na}+\mathrm{Si}$, and $\mathrm{K}+\mathrm{A} l+\mathrm{Si}$ phases were observed on the surface and the reacted layer was 3 to $20 \mu \mathrm{m}$ thick. Although the hydration reaction for these tests appears to be accelerated relative to previously described $202 \mathrm{U}$ samples, the extent of reaction is still 500-1000X less than that observed with $202 \mathrm{~A}$ glass.

\section{CONCLUSIONS}

The blank experiments indicate that radiolysis products are concentrated in the thin films of water that condense on solid components in an unsaturated test environment. The amount of nitrate and nitrite produced in the alpha blank tests is consistent with that expected with a yield of $G\left(N_{X}\right)=\sim 2$ molecules $/ 100 \mathrm{eV}$. These radiolytic products may form nitric acid with a resultant $\mathrm{pH}$ decrease of a solution in contact with the samples. Faster glass alteration rates are observed in an irradiated vapor phase environment as evidenced by the greater thickness of the reacted layer and abundance of secondary phases on the glass surface. Additionally, the assemblage of secondary phases that precipitate in the irradiated environment appears to differ from that in a nonirradiated environment. The cause of the accelerated reaction under irradiated conditions and the 
exact radiolytic products responsible for the glass reaction have yet to be established. It must also be stressed that the radiation field used in the present tests is several orders of magnitude greater than that expected in the tuff repository environment, and was used only to observe whether any effect of radiation on glass reaction could be observed.

To further qualify the radiation effect, we are (1) repeating the hydration experiments with $202 \mathrm{~A}$ glass under irradiated conditions, (2) performing hydration experiments at lower temperatures over longer time periods "(3) using a range of glass compositions, and (4) using total gamma-alpha dose rates that are more representative of repository storage conditions. The results of the range of tests will be available prior to startup of the DWPF and will be used in designing a waste package that can meet regulations for radionuclide release and transport under unsaturated conditions.

\section{ACKNOWLEDGMENTS}

Work supported by the U.S. Department of Energy, Office of Environmental Restoration and Waste Management, under Contract W-31-109-ENG-38.

\section{REFERENCES}

1. L. R. Pederson and G. L. McVay, J. Am. Ceram. Soc. 66, 863-867 (1983).

2. G. L. McVay, W. J. Weber, and L. R. Pederson, Nucl. and Chem. Waste Mgmt. 2, 103-108 (1981).

3. W. J. Weber, Nucl. Inst. and Methods in Phys. Res, B32, 471-479 (1988).

4. W. G. Burns, A. E. Hughes, J. A. C. Marples, R. S. Nelson, and A. M. Stoneham, J. Nucl. Mater. 107, 245 (1982).

5. A. Barkatt, A. Barkatt, and W. Sousanpour, Nuc1. Tech. 60, 218-227 (1983).

6. G. L. McVay and L. R. Pederson, J. Am. Ceram. Soc. 64, 154-158 (1984).

7. J. K. Bates, D. F. Fischer, and T. J. Gerding, Argonne National Laboratory report ANL-86-62 (1986).

8. J. K. Bates, T. J. Gerding, D. F. Fischer, and W. L. Ebert, Lawrence Livermore National Laboratory report UCRL-15991 (1987).

9. T. A. Abrajano, Jr., J. K. Bates, T. J. Gerding, and W. L. Ebert, Argonne National Laboratory report ANL-88-14 (1988).

10. W. L. Ebert, J. K. Bates, and T. J. Gerding, Argonne National Laboratory report ANL-90/13 (1990).

11. W. L. Ebert, J. K. Bates, T. A. Abrajano, Jr., and T. J. Gerding, Ceram. Trans. 9 , 155-164 (1990).

12. M. Aubar et al., NSRDS-NBS-43 (1973).

13. W. S. Walters and S. J. Wisberg, AERE Report R-11984 (1986).

14. Site Characterization Plan, U.S. Department of Energy, Office of Civilian Radioactive Waste Management, DOE Report DOE-RW-0199 (1988).

15. R. G. Baxter, Savannah River Laboratory report DP-1606 (1988).

16. R. D. Aines, Am. Ceram. Soc., 3rd Inter. Symp. on Nuclear Waste Disposal, Chicago, IL, 1986.

17. J. K. Linacre and W. R. Marsh, AERE Report R-10027 (1981).

18. S. C. Lind, Radiation Chemistry of Gases, Am. Chem. Soc. Monograph Ser., Reinhold Publishing Corp., NY (1961).

19. J. K. Bates, T. A. Abrajano, Jr., W. L. Ebert, J. J. Mazer, and T. J. Gerding, Mat. Res. Soc. Symp. Proc. Vol. 123, 237-244 (1989).

20. W. L. Ebert and J. K. Bates, Mat. Res. Soc. Symp. Proc. Vol. 176, 339-346 (1990).

21. H. Yokayama, H. P. Hermansson, H. Christenson, I. K. Bjorner, and L. Werme, Mat. Res. Soc. Symp. Proc. Vol. 44, 601-608 (1985).

22. T. A. Abrajano, Jr., J. K. Bates, and J. J. Mazer, J. Non-Cryst. Sol. $108,269-288$ (1989).

23. D. T. Reed and R. A. Van Konynenburg, Am. Nucl. Soc. Symp., Las Vegas, Nevada, 1991 (in press). 